\title{
Optimization Diagnosis of Breast Cancer Vertebral Metastases
}

\author{
Dinara Zhoobasarova', Altynai Sadykova ${ }^{1}$, Zhanibek Muratov ${ }^{2}$, Feruza Abdraeva ${ }^{1}$, \\ Ainisa Aitieva1, Zhyldyz Aitieva1, Dilaram Zheenbekova1, Fatima Ismailova1, \\ Umutai Tazhibaeva ${ }^{1}$, Asel Murzabek Kyzy' ${ }^{1}$ Zhypargul Abdullaeva ${ }^{3 *}{ }^{\circledR}$, Zhanangul Kochkorbaeva1, \\ Tazhibaev Maksatbek ${ }^{4}$, Bekbolot Keneshbaev ${ }^{5}$, Meerzhan Kadyrberdieva ${ }^{6}$, Nurilia Sherieva7
}

\footnotetext{
${ }^{1}$ Department of Internal Disorders, Faculty of International Medical, Osh State University, Osh, Kyrgyzstan

${ }^{2}$ Department of Pathology and Basic Clinical Pharmacology, Faculty of International Medical, Osh State University, Osh, Kyrgyzstan ${ }^{3}$ Department of Science and Research, Osh State University, Osh, Kyrgyzstan

${ }^{4}$ Department of Surgical Disorders, Faculty of Medical, Osh State University, Osh, Kyrgyzstan

${ }^{5}$ Department of Anatomy, Histology and Normal Physiology, Faculty of International Medical, Osh State University, Osh, Kyrgyzstan ${ }^{6}$ Department of Nursing Development, Institute Named after S.B. Danyarov, Bishkek, Kyrgyzstan

${ }^{7}$ Center of Health and Medical Technologies Development, Bishkek, Kyrgyzstan

Email: *jypar.science@oshsu.kg
}

How to cite this paper: Zhoobasarova, D. Sadykova, A., Muratov, Z., Abdraeva, F., Aitieva, A., Aitieva, Z., Zheenbekova, D., Ismailova, F., Tazhibaeva, U., Kyzy, A.M., Abdullaeva, Z., Kochkorbaeva, Z., Maksatbek, T., Keneshbaev, B., Kadyrberdieva, M. and Sherieva, N. (2021) Optimization Diagnosis of Breast Cancer Vertebral Metastases. Advances in Breast Cancer Research, 10, 156-164.

https://doi.org/10.4236/abcr.2021.104013

Received: August 8, 2021

Accepted: September 11, 2021

Published: September 14, 2021

Copyright (C) 2021 by author(s) and Scientific Research Publishing Inc. This work is licensed under the Creative Commons Attribution International License (CC BY 4.0).

http://creativecommons.org/licenses/by/4.0/

\begin{abstract}
The article is describing results after analysis of research conducted in Osh Interregional Oncology Center under the Ministry of Health in the Kyrgyz Republic. X-ray computed tomography, magnetic resonance imaging analyses were made for optimization diagnosis determination in patients with breast cancer vertebral metastases. According to the obtained data, the frequency of vertebral metastases in breast cancer was observed as well as the timing of their detection depending on the detection of the primary tumor. In addition, the necessity for early screening of vertebral metastases was explained.
\end{abstract}

\section{Keywords}

Breast Cancer, Diagnosis, Vertebral Metastases, Decrease in Life Quality, Primary Tumor, Bone Metastases

\section{Introduction}

Breast Cancer $(\mathrm{BC})$ is one of the most frequent pressing problems in oncology. In recent years, breast cancer has been ranked first among malignant tumors in women. According to published information, new breast cancer cases diagnosed in 2008 were 1.38 million with almost $50 \%$ of all breast cancer patients and ap- 
proximately $60 \%$ of deaths occurring in developing countries [1]. The incidence of cancer in this localization over the past 20 years has increased by $40 \%$ and there is a further tendency of its growth; the difference in breast cancer incidence and prognosis was detected in ethnic groups' variety, among patients who have been observed for 5 years or more, a greater proportion in patients with breast tumors was $20.6 \%$ [2]. In recent years, breast cancer has been increasingly registered in developing countries, where mortality is growing at an outstripping pace. According to the WHO, out of half a million women who died from breast cancer in 2012, more than half (58\%) lived in countries with a low standard of living, in which the chances of survival do not exceed $20 \%$. WHO experts explain this fact by the underdeveloped health care system and the limited access of patients to early diagnosis and treatment, even to supportive and palliative care [3] [4] [5].

Success in breast cancer treatment depends on disease stage, history of the family, and other characteristics, in which analysis of qualitative characteristics with diagnostics, staging and treatment will allow it to reduce recurrence risks [5]. Breast cancer can be typically detected by screening, before the development of symptoms or after a woman notices a lump, in which mass is seen on a mammogram [6]. BC incidence by age and race/ethnicity was determined with the incidence of molecular subtypes, differing in risk factors and prognosis, age and race/ethnicity [7].

The incidence of bone metastases in cancer patients is high. Out of 1000 pathoanatomical studies of those who died from malignant tumors, bone metastases are detected in $25 \%$ - $30 \%$ of cases. In terms of the frequency of localization of metastatic lesions, the skeleton ranks third, after the lungs and liver, according to several authors, metastases account for $96 \%$ of all spinal tumors [8].

Vertebral metastases are common in breast cancer [9], adversely affecting life quality and disease prognosis which are usually responsive to hormonal therapy and often require surgical intervention. The treatment of spinal metastases requires interdisciplinary collaboration and must be considered according to each patient's diagnosis [10]. Screening and earlier diagnosis of vertebral metastases can help to effective treatment and a positive breast cancer prognosis. Optimization of the vertebral metastases diagnosis in breast cancer is requiring urgency as spinal metastasis can be determined before the appearance of the primary tumor signs and many years after the radical removal of the primary breast tumor. Anatomical distribution of vertebral metastases requiring surgical treatment is represented in Figure 1, where combined anterior-posterior simultaneous approach involved the lateral elements of spinal column with significant paraspinal extension and anterior-posterior staged approach used at junctional zones with preexisting spinal deformity [11].

Recently, spinal radiosurgery is proposed for the local control of vertebral metastases as primary treatment, considered as initial treatment for radioresistant tumors, such as melanoma and renal cell carcinoma [12].

The Magnetic Resonance Imaging (MRI) is the gold standard method especially 


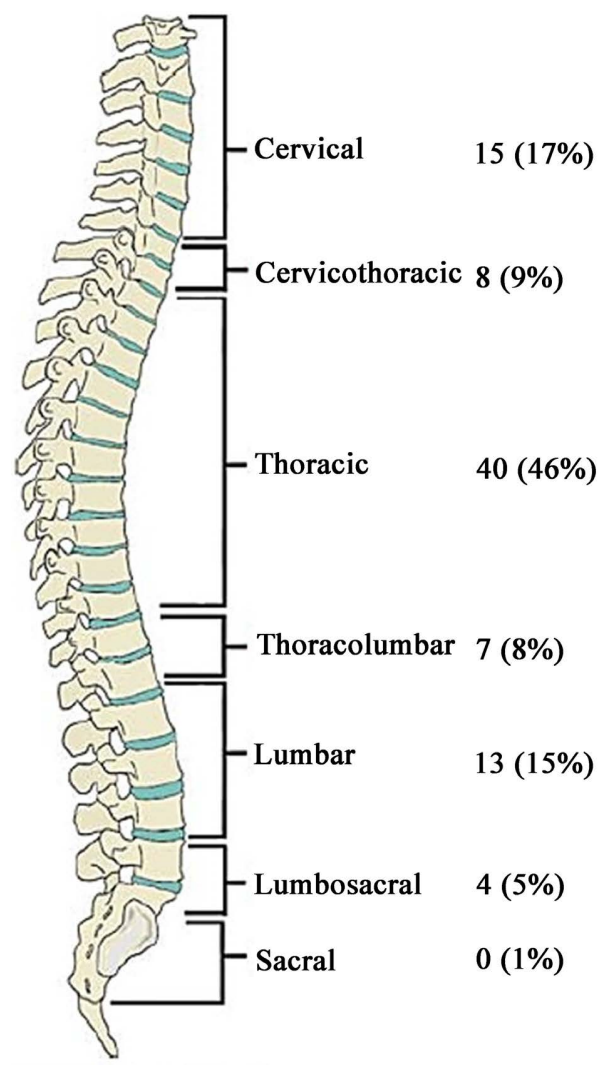

Figure 1. Anatomical distribution of spinal metastases requiring surgical treatment (represented from reference [11]).

informative and is a priority high-tech evaluation of vertebral metastasis with the highest sensitivity and specificity in the detection (98.5\% vs. $98.9 \%)$ with an accuracy of $98.7 \%$ [13]. Early diagnosis of metastatic lesions of the spine is very important adequate treatment, which is of great practical importance for increasing the life quality and duration in patients with tumors [14]. Life quality in oncology was explored among two groups of patients: 1) patients with cancer at advanced stage or in palliative care; 2) patients and survivors of specific cancers [15].

\section{Research Methods and Materials}

We examined 78 patients treated and registered at the Osh Interregional Oncology Center under the Ministry of Health of the Kyrgyz Republic from 2008 to 2013. The clinical features were studied depending on the location of the vertebral metastases and the primary tumor. The examination was carried out in full using traditional methods: X-ray of the spine in two projections, computed or magnetic resonance imaging of the spinal column. Depending on the localization of the primary tumor, ultrasound examinations of the mammary gland, abdominal organs, pelvic cavity and retroperitoneal space, chest X-ray and skeletal system were conducted.

The presence of local pain in one or another part of spine was indicated for 
$\mathrm{X}$-ray examination, therefore, at the initial stage of the examination, an overview $\mathrm{X}$-ray of the area of interest of the spine was performed. Despite the latest research methods such as CT and MRI [16], the importance of X-ray diagnostics has not lost its relevance due to its availability. Computed tomography and magnetic resonance imaging are modern highly informative diagnostic methods that allow you to accurately determine the lesion focus, its prevalence, and determine its nature and relationship with the structures of the spinal cord. We used computed tomography in 12 cases and magnetic resonance imaging in 36 cases.

Magnetic resonance imaging performed on HITACHI Aperto LUGENT 0.4T high-field tomographic equipment. The MRI study was performed in the T2-VI, T1-VI modes, with a magnetic field strength of 1.5 Tesla. Scanning was performed in the supine position according to the standard program with obtaining T1, T2 weighted images in FSE sequences in axial, sagittal, frontal projections, with a slice thickness and an inter slice spacing of $2.5 \mathrm{~mm}$. The study complemented by a program with suppression of the signal from adipose tissue (STIR). Study was performed according to ethical declarations about human and animal studies in accordance with the ethical standards of Helsinki and its later amendments.

\section{Results and Discussions}

\subsection{Frequency and Cases in Breast Cancer Disorders}

Often metastasis of breast cancer in the bone occurs by the hematogenous route. At the same time, the possibility of lymphogenous metastasis of breast cancer in the bone has been proven. Metastatic disease is characterized by the spread of tumor cells throughout the body and is responsible for the majority of patient deaths [17]. The skeletal system is most affected by metastases in tumors of various localization, in particular the breast cancer. According to various authors, in breast cancer, bone metastases are manifested in $70 \%-80 \%$ of patients with common forms of the disease, with the most frequently affected lumbar (45.6\%) and thoracic (37.7\%) spine, sacral spine (5.3\%), cervical (11.4\%) [18]. From 33 patients with breast cancer 2 patients with cervical metastasis, 11 patients with cervicothoracic metastasis, 20 patients with thoracolumbar metastasis were observed.

The general frequent staging system for breast cancer is American Joint Committee of Cancer (AJCC) TNM, which is based on tumor size and the locoregional invasion degree by primary tumor $(\mathrm{T})$, the extent of regional lymph node involvement $(\mathrm{N})$ and presence or absence of distant metastases (M) as represented in Table 1 [19].

Indicators of life expectancy are significantly better in patients with single or solitary metastases in breast cancer [20]. In no more than $20 \%$ of patients, bone metastases are the only manifestation of the disease. Bone metastases lead to a decrease in the quality of life and early disability of the patient [21]. To prevent the disability of a patient with breast cancer, it is necessary to carefully examine, periodically conduct magnetic resonance imaging of the axial skeleton. In 10\% 
Table 1. Breast cancer staging (represented from reference [19]).

\begin{tabular}{|c|c|c|c|c|}
\hline Stage & $\mathrm{T}$ & $\mathbf{N}$ & $\mathbf{M}$ & Description \\
\hline 0 & Tis & No & M0 & $\begin{array}{c}\text { Tumor that has not grown beyond its site of origin } \\
\text { and invaded the neighboring tissue. It includes the } \\
\text { DCIS and LCIS. }\end{array}$ \\
\hline IA & $\mathrm{T} 1($ tumor $\leq 20 \mathrm{~mm})$ & No & M0 & $\begin{array}{c}\text { Tumor which is not "in situ" but it is } \leq 20 \mathrm{~mm} \text { in } \\
\text { greater dimension. }\end{array}$ \\
\hline IB & $\mathrm{T} 0$ or $\mathrm{T} 1$ & $\begin{array}{l}\text { N1mi (micro } \\
\text { metastases) }\end{array}$ & M0 & $\begin{array}{l}\text { Tumor } \leq 20 \mathrm{~mm} \text { in greater dimension with nodal } \\
\text { micrometastasis (greater than } 0.2 \mathrm{~mm} \text { and/or more } \\
\text { than } 200 \text { cells, but none greater than } 2 \mathrm{~mm} \text { ). }\end{array}$ \\
\hline IIA & $\begin{array}{c}\text { T0 or T1 } \\
\text { T2 }(20 \mathrm{~mm}<\text { tumor } \leq \\
50 \mathrm{~mm})\end{array}$ & $\begin{array}{l}\text { N1 (metastases in } 1-3 \\
\text { ipsilateral ALN(s) } \\
\text { N0 }\end{array}$ & $\begin{array}{l}\text { M0 } \\
\text { M0 }\end{array}$ & $\begin{array}{l}\text { Tumor } \leq 20 \mathrm{~mm} \text { in greater dimension with } \\
\text { involvement of axillary lymph nodes or tumour from } \\
20 \text { to } 50 \mathrm{~mm} \text { without involvement of any ALNs. }\end{array}$ \\
\hline IIB & $\begin{array}{c}\mathrm{T} 2 \\
\mathrm{~T} 3 \text { (tumor }>50 \mathrm{~mm}\end{array}$ & $\begin{array}{l}\text { N1 } \\
\text { N0 }\end{array}$ & $\begin{array}{l}\text { M0 } \\
\text { M0 }\end{array}$ & $\begin{array}{l}\text { Tumor from } 20 \text { to } 50 \mathrm{~mm} \text { with involvement of ALNs } \\
\text { or tumor }>50 \mathrm{~mm} \text { without involvement of any ALNs }\end{array}$ \\
\hline IIIA & $\begin{array}{c}\mathrm{T} 0, \mathrm{~T} 1 \text { or } \mathrm{T} 2 \\
\mathrm{~T} 3\end{array}$ & $\begin{array}{c}\mathrm{N} 2 \text { (metastases in } 4-9 \\
\text { ipsilateral } \\
\text { ALNs) } \\
\text { N1 or N2 }\end{array}$ & $\begin{array}{l}\text { M0 } \\
\text { M0 }\end{array}$ & $\begin{array}{l}\text { Tumor }>50 \mathrm{~mm} \text { with spread to ALNs, or tumor of } \\
\text { any size with metastases in ALNs which are knitted to } \\
\text { each other or with the surrounding tissue. }\end{array}$ \\
\hline IIIB & $\begin{array}{l}\text { T4 (tumor of any size } \\
\text { with direct extension } \\
\text { to the chest wall } \\
\text { and/or to the skin }\end{array}$ & N0, N1, N2 & M0 & $\begin{array}{l}\text { Tumor of any size with metastases into the skin, } \\
\text { chest wall or internal LNs of the mammary gland. }\end{array}$ \\
\hline IIIC & Any $\mathrm{T}$ & $\begin{array}{l}\text { N3 (metastases in } \geq 10 \\
\text { ALNs, or in } \\
\text { infra-clavicular LNs or } \\
\text { ipsilateral internal } \\
\text { mammary LNs) }\end{array}$ & M0 & $\begin{array}{l}\text { Tumor of any size with a more widespread metastases } \\
\text { and involvement of more LNs. }\end{array}$ \\
\hline IV & Any $\mathrm{T}$ & Any N & $\begin{array}{l}\text { M1 (distant } \\
\text { organs' } \\
\text { metastases) }\end{array}$ & $\begin{array}{l}\text { Any tumor spreads to parts of the body that relocated } \\
\text { far removed from the chest (bones, lungs, liver or } \\
\text { distant LNs). }\end{array}$ \\
\hline
\end{tabular}

ALN axillary lymph node, DCIS ductal carcinoma in situ, LCIS lobular carcinoma in situ, LN lymph node. •T2, T3 and T4 tumors with nodal micrometastases $(\mathrm{N} 1 \mathrm{mi})$ are staged using the $\mathrm{N} 1$ category; $\bullet \mathrm{M} 0$ means that there are no clinical or radiographic evidence of distant metastases. It includes also M0(i+) that indicates the presence of tumor cells or deposits $<0.2 \mathrm{~mm}$ detected microscopically or by molecular techniques in circulating blood, bone marrow or other nonregional nodal tissue in a patient without clinical and radiographic evidence of distant metastases; •Stage 3a is broadly known as a local spread of breast cancer; •T4 does not include the invasion of dermis alone; $\bullet$ If a patient presents with M1 disease prior to neoadjuvant systemic therapy, the stage considered stage IV and remains stage IV regardless of response to neoadjuvant therapy; •Stage designation may be changed if postsurgical imaging studies reveal the presence of distant metastases, provided the studies performed within 4 months of diagnosis in the absence of disease progression, and provided the patient has not received neoadjuvant therapy.

of cases, metastases are the first manifestation of a malignant process [22], while the primary tumor often remains unrecognized. It is also well known that metastasis to the skeleton can occur against the background of complete clinical well-being on the part of the primary tumor, sometimes, 10 - 20 years after its radical removal. 
In 78 patients with vertebral metastases, breast cancer was observed in 33 patients, who amounted to $42.3 \%$, and this confirms the literature data on more frequent lesions of the spine in breast cancer. It should be noted that vertebral metastases were detected at various times after the identification of primary focus. In our practice, out of 33 breast cancer patients, simultaneous detection of metastases and primary tumor was observed in 7 cases, after 6 months, vertebral metastasis was found in 3 cases, from 6 months to 12 months in 5 cases, from 1 year to 3 years were 9 cases, from 3 to 5 years were 2 cases, from 5 to 10 years were 5 cases and 2 cases from 10 years. Therefore, for early detection of vertebral metastasis, it is necessary to periodically and carefully examine the patient for many years.

Age of patients with breast cancer metastatic lesions of spine ranged from 31 to 71 years and majority of patients coincide at $41-50$ years old. Clinical features in all cases observed with pain syndrome in affected spine, more often in the lumbosacral spine, since in most cases the lumbar spine of the patients was affected. Thoracic spine ranks second in terms of the lesions frequency. Back pains were of varying intensity from minor aching to intolerable pain. Usually, the pain is transient at first and gradually progresses, less often, it occurs sharply from the very beginning to its intense.

Pain in the lumbar region of the spine radiated to the lower extremities of 65 (83.3\%) patients, increased with a change in body position in $74(94.8 \%)$ patients, and physical activity in 13 (66.6\%). In 69 (88.4\%) patients, pain was constant. In 69 cases, pain in the spine was the first manifestation of metastatic lesions of the spine. Back pain was accompanied by other neurological manifestations such as numbness (32\%), muscle weakness (18\%), limitation of lower limb movements (36\%) up to complete immobility (12\%), and pelvic dysfunction $(47 \%)$. Common symptoms in some cases were fever, weight loss and general weakness.

The duration of the disease depends on the stage of the disease in the detection of metastases in the spine and the method of treatment.

Treatment of metastatic lesions of the spine accompanied by certain difficulties, due to the most frequent manifestation of metastasis against the background of generalization of the malignant process, damage to other organs and the severe somatic condition of patient.

The method choice in treatment depends on time of $\mathrm{d}$ metastases detection, the presence of other metastases, and the degree of prevalence of the tumor process. In general, the overwhelming number of patients (69.2\%) received various methods of anticancer treatment (radiation therapy, chemotherapy). The rest of patients did not receive special treatment due to somatic condition severity and the treatment categorical refusal. Symptomatic treatment was carried out in 9 patients appointed with painkillers.

\subsection{Optimization Diagnosis}

For all above locations of the primary tumor, periodic screening is necessary, as 
late detection leads to medical emergencies. Severe pain due to compression of the nerve roots and cauda equina metastasis [23] of the spine, spinal fractures, paresis, paralysis of the lower extremities, general fatigue, difficulty sleeping, depression, lymph nodes brachial plexopathies, pain which reduces patients quality of life and lead to disability [24]. It is also necessary to draw up an algorithm for the early diagnosis of vertebral metastases in breast cancer [25].

Diagnosis of vertebral metastasis in breast cancer diseases is one of the most difficult and urgent clinical problems due to anatomical features, where difficulty of differential diagnosis based on neurological signs, the frequency and severity of the manifestations of diseases and their consequences [26]. The possibilities of specific therapy are often limited due to the frequent need for repeated treatment, significant dissemination of lesions, as well as the migratory nature of the pain.

In several patients with generalized metastases, chemotherapy is generally not possible due to the severity of condition. In this situation, the fight against pain and other painful symptoms of vertebral metastasis in breast cancer becomes of primary importance. Often the only way to relieve suffering is through the palliative use of strong pain relievers. Unfortunately, these drugs do not always show the ability to control pain in the patient, and some patients cannot stand the side effects they cause.

The diagnostic algorithm was in following sequence:

1) Patients with diagnosed breast cancer underwent an X-ray of the spine when pain appeared;

2) CT or MRI in case of spinal metastasis was suspected. Pain in metastatic lesions of the spine is not particularly specific, because of which many patients with metastatic spine lesions were for a long time (1 - 3 years) under the neurologists, neurosurgeons and orthopedists supervision. To optimize the diagnosis it is necessary to periodically examine entire spine for early detection of vertebral metastases. Careful examination usually revealed the cause of pain.

\section{Conclusions}

When observing and treating patients for breast cancer, it is necessary to diagnose the entire skeletal system, and explain to the patient about the next visits for examination and screening of possible metastases. Explain the positive aspects of periodic examination of the skeletal system, in particular the spine.

Based on the above, the following conclusions were made:

1) The need to create an algorithm for the diagnosis of vertebral metastases in breast cancer disease;

2) Early detection of vertebral metastases improves the effectiveness of treatment;

3) Effective treatment in the early stages of vertebral metastases improves the patient's quality of life and prevents disability.

\section{Conflicts of Interest}

The authors declare no conflicts of interest regarding the publication of this paper. 


\section{References}

[1] Akram, M., Iqbal, M., Daniyal, M. and Khan, A.U. (2017) Awareness and Current Knowledge of Breast Cancer. Biological Research, 50, Article No. 33. https://doi.org/10.1186/s40659-017-0140-9

[2] Ismailova, G.N., Ermekbaeva, B.A., Zhusupova, B.T., Iskakova, A.M., Esmagambetov, Z.A., Shaimardanova, G.M. and Kumisbekova, R.K. (2014) Breast Cancer: Modern Approaches to Diagnosis and Treatment. Clinical Medicine of Kazakhstan, 4, 10-19.

[3] Tan, B.K.T., Lim, G.H., Czene, K., Hall, P. and Chia, K.S. (2009) Do Asian Breast Cancer Patients Have Poorer Survival than Their Western Counterparts? A Comparison between Singapore and Stockholm. Breast Cancer Research, 11, R4. https://doi.org/10.1186/s40659-017-0140-9

[4] Alieva, O.D. (2006) Application of Magnetic Resonance Imaging for Diagnosing the Prevalence of Breast Cancer and Monitoring the Quality of Treatment for Metastases. Dissertation, GOUDPO Kazan State Medical Academy, Kazan, 123 p.

[5] Kaprina, E.D., Starinsky, V.V. and Petrova, G.V. (2019) The State of Cancer Care for the Population of Russia in 2018. Moscow, 2019.

[6] American Cancer Society (2019) Breast Cancer Facts \& Figures 2019-2020. American Cancer Society, Inc., Atlanta, 44 p.

[7] Acheampong, T., Kehm, R.D., Terry, M.B., Argov, E.L. and Tehranifar, P. (2020) Incidence Trends of Breast Cancer Molecular Subtypes by Age and Race/Ethnicity in the US from 2010 to 2016. JAMA Network Open, 3, e2013226. https://doi.org/10.1001/jamanetworkopen.2020.13226

[8] Galeev, M.G. (1997) Evaluation of the Effectiveness of the Method of Palliative Treatment of Patients with Breast Cancer with Damage to the Bones of the Skeleton. Dissertation, Medical Sciences, 24.

[9] Ju, D.G., Yurter, A., Gokaslan, Z.L. and Sciubba, D.M. (2014) Diagnosis and Surgical Management of Breast Cancer Metastatic to the Spine. World Journal of Clinical Oncology, 5, 263-271. https://doi.org/10.5306/wjco.v5.i3.263

[10] Delank, K.S., Wendtner, C., Eich, H.T. and Eysel, P. (2011) The Treatment of Spinal Metastases. Deutsches Arzteblatt International, 108, 71-80. https://doi.org/10.3238/arztebl.2011.0071

[11] Shehadi, J.A., Sciubba, D.M., Suk, I., Suki, D., Maldaun, M.V., McCutcheon, I.E., Nader, R., Theriault, R., Rhines, L.D. and Gokaslan, Z.L. (2007) Surgical Treatment Strategies and Outcome in Patients with Breast Cancer Metastatic to the Spine: A Review of 87 Patients. European Spine Journal: Official Publication of the European Spine Society, the European Spinal Deformity Society, and the European Section of the Cervical Spine Research Society, 16, 1179-1192. https://doi.org/10.1007/s00586-007-0357-3

[12] Joaquim, A.F., Ghizoni, E., Tedeschi, H., Pereira, E.B. and Giacomini, L.A. (2013) Stereotactic Radiosurgery for Spinal Metastases: A Literature Review. Einstein (Sao Paulo, Brazi), 11, 247-255. https://doi.org/10.1590/S1679-45082013000200020

[13] Kurisunkal, V., Gulia, A. and Gupta, S. (2020) Principles of Management of Spine Metastasis. Indian Journal of Orthopaedics, 54, 181-193. https://doi.org/10.1007/s43465-019-00008-2

[14] Shrestha, A., Martin, C., Burton, M., Walters, S., Collins, K. and Wyld, L. (2019) Quality of Life versus Length of Life Considerations in Cancer Patients: A Systematic Literature Review. Psycho-Oncology, 28, 1367-1380. https://doi.org/10.1002/pon.5054

[15] Sibeoni, J., Picard, C., Orri, M., Labey, M., Bousquet, G., Verneuil, V. and Revah-Levy, 
A. (2018) Patients' Quality of Life during Active Cancer Treatment: A Qualitative Study. BMC Cancer, 18, 951. https://doi.org/10.1186/s12885-018-4868-6

[16] Vercher-Conejero, J.L., Pelegrí-Martinez, L., Lopez-Aznar, D. and Cózar-Santiago, M. (2015) Positron Emission Tomography in Breast Cancer. Diagnostics (Basel, Switzerland), 5, 61-83. https://doi.org/10.3390/diagnostics5010061

[17] Redig, A.J. and McAllister, S.S. (2013) Breast Cancer as a Systemic Disease: A View of Metastasis. Journal of Internal Medicine, 274, 113-126. https://doi.org/10.1111/joim.12084

[18] Sergeev, N.I. (2016) The Role and Place of Modern Imaging Methods in the Diagnosis and Assessment of the Results of Conservative Treatment of Patients with Metastatic Skeletal Lesions. Dissertation, Federal State Budgetary Institution Russian Research Center of X-Ray Radiology, Ministry of health of the Russian Federation, Moscow, $233 \mathrm{p}$.

[19] Pesapane, F., Downey, K., Rotili, A., Cassano, E. and Koh, D.M. (2020) Imaging Diagnosis of Metastatic Breast Cancer. Insights into Imaging, 11, 79. https://doi.org/10.1186/s13244-020-00885-4

[20] Lun, D.X., Xu, L.N., Wang, F., Yang, X.G., Yu, X.C., Zhang, G.C. and Hu, Y.C. (2019) Prognostic Differences in Patients with Solitary and Multiple Spinal Metastases. Orthopaedic Surgery, 11, 443-450. https://doi.org/10.1111/os.12470

[21] Nooh, A., Goulding, K., Isler, M.H., Mottard, S., Arteau, A., Dion, N. and Turcotte, R. (2018) Early Improvement in Pain and Functional Outcome But Not Quality of Life after Surgery for Metastatic Long Bone Disease. Clinical Orthopaedics and Related Research, 476, 535-545. https://doi.org/10.1007/s11999.0000000000000065

[22] Suva, L.J., Griffin, R.J. and Makhoul, I. (2009) Mechanisms of Bone Metastases of Breast Cancer. Endocrine-Related Cancer, 16, 703-713. https://doi.org/10.1677/ERC-09-0012

[23] Walid, M.S., Ajjan, M., Johnston, K.W. and Robinson, J.S. (2008) Cauda Equina Syndrome-Think of Cancer. The Permanente Journal, 12, 48-51. https://doi.org/10.7812/TPP/07-054

[24] Irvin, W., Muss, H.B. and Mayer, D.K. (2011) Symptom Management in Metastatic Breast Cancer. The Oncologist, 16, 1203-1214. https://doi.org/10.1634/theoncologist.2011-0159

[25] Curtin, M., Piggott, R.P., Murphy, E.P., Munigangaiah, S., Baker, J.F., McCabe, J.P. and Devitt, A. (2017) Spinal Metastatic Disease: A Review of the Role of the Multidisciplinary Team. Orthopaedic Surgery, 9, 145-151.

https://doi.org/10.1111/os.12334

[26] Mendez, J.S. and De Angelis, L.M. (2018) Metastatic Complications of Cancer Involving the Central and Peripheral Nervous Systems. Neurologic Clinics, 36, 579-598. https://doi.org/10.1016/j.ncl.2018.04.011 